\title{
A árvore Carolina Maria de Jesus: uma literatura vista de longe
}

Gilmar Penteado $^{1}$

Em Literatura e resistência (2002), Alfredo Bosi dedica um parágrafo curto à escritora Carolina Maria de Jesus, autora de Quarto de despejo: diário de uma favelada. Para ser mais preciso, Bosi empregou quatro frases ao se referir à escritora negra, favelada, catadora de papel, mãe solteira de três filhos, com apenas dois anos de educação formal, que fez de seu diário de fome e de miséria o que se costuma chamar de best-seller, um texto com mais de 1 milhão de exemplares vendidos por todo o mundo. Para ser ainda mais exato, o conhecido crítico e escritor usou 76 palavras, oito vírgulas e quatro pontos para se referir à escritora que movimentou o cenário da literatura brasileira no começo dos anos 1960, superando inclusive as vendas do renomado e então imbatível Jorge Amado.

E, além de curta, a referência foi usada por Bosi para dizer que a autora não seria mais citada. Explicando melhor: Carolina surgiu rápido no texto para não mais aparecer, justamente em um capítulo intitulado "A escrita e os excluídos". Ou seja, a escritora seria um caso à parte, quase uma extraterrestre, e, por exigir muito espaço, teria espaço algum. Mas vamos logo à citação, que de tão sucinta não vai nos tomar espaço nem tempo.

Outro exemplo notável, e já plenamente urbano, de cultura de fronteira é o de uma favelada, apenas alfabetizada, que registrou o seu cotidiano em um diário pungente, publicado em 1960 com o título de Quarto de despejo. Falo de Carolina de Jesus, cuja obra foi traduzida para as principais línguas cultas do mundo, reproduziuse amplamente e atingiu um milhão de exemplares. $\mathrm{O}$ romancista Alberto Moravia prefaciou a edição italiana. Sem dúvida, um tento difícil de repetir-se (Bosi, 2002, p. 261).

E isso é tudo.

Na citação acima, as expressões "exemplo notável" e "tento difícil de repetir-se" parecem ter a função de encerrar o assunto. E foi isso que fez Bosi, ao partir para a narrativa que realmente o interessava, que era sua própria experiência em dar aula a um grupo de operários de Osasco

\footnotetext{
${ }^{1}$ Doutorando em estudos literários pela Universidade Federal do Rio Grande do Sul (UFRGS), Porto Alegre, RS, Brasil. E-mail: gilmar.penteado@uol.com.br
} 
(Grande São Paulo) durante o período da ditadura militar. Carolina foi apenas uma conexão, ou o trampolim, ou o gancho - se quisermos usar o jargão jornalístico. Nenhum problema em relação a isso. A dúvida é Carolina merecer apenas um parágrafo de conexão em um livro de 297 páginas intitulado - vale a pena mencionar de novo - Literatura e resistência.

A leitura sob esse enfoque traz a tentação de destilarmos uma crítica mordaz à obra de Bosi. Mas é preciso cautela. Afinal, Bosi citou a catadora de papel, coisa que muitos outros críticos literários, sempre tão atentos ao cânone, não fizeram. Bosi revela uma admiração à Carolina. E uma citação é melhor que nada, podemos dizer assim; tratar Carolina como extraterrestre talvez seja mais producente do que tratá-la como um fantasma. Bosi não é responsável pela incompreensão ou pelo silêncio que cerca a obra de Carolina. Ou pelo menos não está sozinho nisso. Carolina permanece desconhecida pela maioria do público leitor atual e, os que a reconhecem - geralmente pessoas ligadas de alguma forma ao ensino e à pesquisa da literatura brasileira - a tratam como a escritora de uma obra só. Mas Carolina era uma autora profícua, lia e produzia literatura todos os dias. Escrevia de forma ininterrupta, com sua letra de forma; quase nunca rasurava seu texto. Teve quatro livros publicados em vida (dois diários, entre eles Quarto de despejo, um romance e um livro de provérbios) e três póstumos (um de memórias, um de poesias e outro diário, um compilado de vários períodos). E muitos de seus textos ainda permanecem inéditos.

Carolina é uma escritora peculiar: é indiscutível. De talento extraordinário, usou as formas que tinha na luta pela sobrevivência. Queria salvar a si e a seus filhos da fome, da vida dura na favela do Canindé, na capital paulista, no final dos anos 1950, além de ascender socialmente, mas também ser reconhecida como artista. Por isso, sua obra confunde e exige que o crítico saia de sua zona de conforto. Se Carolina não serve para o cânone, o cânone também não serve para Carolina. Não é de um guardião de autores e obras cultas que sairá a explicação para a complexidade da narrativa de uma catadora de papel que desafiou as normas sociais.

Deixado o cânone de lado, é preciso conter o outro extremo: o dos entusiastas. Aqueles que se deslumbram com o talento "improvável" de Carolina, que passam a apontá-la como um "exemplo notável", "um tento difícil de repetir-se" e outras tantas expressões similares. E não vão além. Não rompem a barreira do deslumbramento. Daí de escritora- 
fantasma a escritora-extraterrestre é um passo. Mais de 50 anos após a publicação do primeiro livro, Carolina ainda é muitas vezes descrita pela academia - dentro dela, alguns entusiastas de seu trabalho - por sua escrita exótica e improvável. Um deslumbramento na maioria das vezes pouco produtivo.

Escritora pioneira, sem dúvida. Mas basta um olhar mais amplo para verificarmos que Carolina não está e nunca esteve sozinha. Basta tomarmos como referência a obra do italiano Franco Moretti para começarmos a duvidar que a escritora favelada seja um simples fenômeno, um acidente, uma anomalia. Ou seja, ela não se encerra em si mesma. Moretti não escreveu sobre Carolina, ao contrário de seu compatriota Alberto Moravia, que assinou o prefácio da edição italiana. No entanto, sua obra crítica, sua atenção à pesquisa quantitativa, sua aproximação entre análise estatística e geografia cultural, seu interesse pelos chamados "erros" na literatura, pelo surgimento e desaparecimento de estilos, podem iluminar a trajetória dessa notável escritora brasileira. E também a decifrar as razões que levaram à permanência da obra de Carolina, ressuscitada a partir da década de 1990 por pesquisas universitárias nas áreas de sociologia, história e literatura, e por escritores vindos da periferia urbana de São Paulo.

Em sua resistência ao close reading de grandes livros e autores, Moretti se volta a gráficos da história quantitativa, mapas e árvores diagramáticas em sua obra A literatura vista de longe (2008). Ele aposta em uma ciência da literatura que descarte esse nosso vício de só tentar compreender as singularidades. Seu interesse é tentar explicar padrões gerais em uma sucessão de obras ao longo do tempo, pois não acredita que o estudo de obras individuais seja suficiente para se chegar a uma ideia da literatura como um sistema coletivo. Os resultados são perturbadores para a história literária oficial, acostumada a visões curtas. Moretti aposta no caráter cumulativo; é um inimigo do rigor analítico do objeto fechado em si. Defende "um distanciamento em relação ao texto em sua concretude" (Moretti, 2008, p. 7). É o que ele chama de distant reading, no qual a distância não é um obstáculo, mas uma forma específica de conhecimento.

Apesar de seus modelos abstratos de explicação para a história, Moretti defende que as consequências são para lá de concretas. Iluminam a eclosão e o desaparecimento de uma série de subgêneros literários; torna a renovação um processo muito mais rico, mais 
intrigante. Para ele, um antídoto contra a crescente queda pelo interesse na literatura. No capítulo "Árvores", Moretti aponta uma correlação sistemática entre a forma e a história por meio de árvores evolutivas, ou diagramas morfológicos (2008, p. 114). Dos livros de biologia para a crítica da cultura, poderíamos simplificar assim o processo de construção dessas árvores evolutivas.

Moretti debruça-se sobre mapas, gráficos e árvores para tabular a ascensão popular do romance. O resultado é perturbador, sim, mas o método parece bastante apropriado para analisar a também perturbadora obra de Carolina e seus frutos. O objeto inicial de estudo de Moretti é o romance, mas o surgimento e a consolidação de um gênero literário estão no centro dessa análise. É acima de tudo a história das estruturas literárias. Quarto de despejo é um diário, que não era - e ainda não é - aceito facilmente pelo cânone. Com exceções para os escritores cultos que resolveram perder algum tempo com esse tipo de narrativa. É o diário de autor, o diário íntimo de mulheres de classe média ou alta, o diário de viagem, o diário de campo, quase sempre com um subtítulo para lhe dar algum tipo de nobreza. Mas Carolina trazia agravantes: era pobre e com poucos anos de ensino formal; queria dominar a norma culta, mas estava longe disso.

Nessa correlação entre a forma e a história, tão defendida por Moretti, as décadas de 1950 e 1960 trazem novos ventos à América Latina, e a São Paulo de Carolina. É um novo ciclo temporal, de uma democracia embrionária, de movimentos de massa, de interesse pela voz dos excluídos. A favela passou a despertar curiosidade, os dramas da favela ganhavam leitores. A narrativa do diário foi vista sob uma nova função social, era um veículo para narrar a vida dos excluídos. O testemonio ganhou status de gênero literário, principalmente pela interferência de Cuba, mais precisamente através do concurso literário Casa de las Americas. Letrados militantes de esquerda se propunham a uma parceria com iletrados ou semiletrados nos chamados depoimentos etnográficos - o excluído narrava oralmente sua vida a um sociólogo, jornalista ou antropólogo, que se encarregava da escrita, prometendo uma neutralidade, que sabemos hoje inalcançável. Diário, memória, autobiografia ganharam status de literatura, pelo menos para a esse grupo de intelectuais ligados a movimentos sociais.

É nesse contexto político-social que o jornalista Audálio Dantas encontra Carolina na favela do Canindé, em 1958. É nesse contexto que 
ele se impressiona pelo diário interrompido da catadora de papel - ela o iniciou em 1955, mas parou depois de 14 dias de registros. Dantas promete publicá-lo em livro se Carolina aceitar retomar o diário. Dois anos depois, o livro Quarto de despejo já é um sucesso antes mesmo de chegar às bancas. As reportagens de Dantas na imprensa paulistana já tinham se encarregado de conquistar futuros leitores.

Poderíamos seguir aqui nas tantas singularidades dessa escritora. Mas é preciso voltar a Moretti, partir para o distant reading. Pensar em dados quantitativos, em gráficos, mapas, árvores. E não se iludir pelo que parece singular, único, "difícil de repetir-se". É o que defendemos aqui. Mas dados quantitativos em literatura brasileira são raros. Pela inexistência de uma tradição, pelo esforço que exige. E como fazer mapas, gráficos, árvores, sem eles? Mais um problema: como conseguir dados quantitativos de autores vindos da periferia urbana que a sociedade culta nem considera como tais? Muitos escreveram, apesar da dificuldade de acesso ao ensino formal. Mas poucos conseguiram publicar - aí está mais um entre tantos aspectos a considerar nesse imenso processo de exclusão social. O quadro é desanimador, temos de admitir.

Carolina não se enquadra facilmente nas teorias disponíveis. É sujeito da narrativa, escreve o que pensa. Seus manuscritos não deixam dúvida. O jornalista é o seu editor, não seu mediador ou intérprete - se Dantas se excedeu ou não nos cortes é outro problema a ser debatido, para o qual não há espaço aqui. Quarto de despejo não é depoimento etnográfico, narrativa de dupla autoria que se tornou a base do testemonio, no qual o excluído dava seu depoimento oral, o intelectual solidário o transcrevia.

Para tornar a coisa ainda mais complexa, Carolina não segue o perfil de herói popular, não tem consciência de classe nem engajamento político-partidário, atributos tão valorizados por intelectuais de esquerda, que se diziam interlocutores neutros da voz dos excluídos. Ela fala mal de favelados, mulheres, baianos. Para o historiador brasileiro José Carlos Sebe Bom Meihy e o brasilianista norte-americano Robert Levine, autores de Cinderela negra: a saga de Carolina Maria de Jesus (1994), a escritora vinda da favela foi repudiada posteriormente por militantes da esquerda justamente por não se submeter a esse perfil de heroína popular. Por um momento, Bosi parece ter razão quando diz que Carolina é um "tento difícil de repetir-se".

Mas se repetiu - pelo menos em muitos aspectos. E se repetiu muitas vezes. Em várias partes do Brasil. No sul do país; em Porto Alegre (RS), 
mais precisamente. Em 1959, quando Carolina ainda escrevia seu diário na favela do Canindé, a empregada doméstica Zeli de Oliveira Barbosa foi morar com o marido e os filhos na Ilhota, favela localizada entre os bairros Cidade Baixa e Azenha, a mesma onde nasceu o cantor e compositor Lupicínio Rodrigues. Ilhota era uma favela próxima do centro da cidade, como a do Canindé. Sofria de problemas graves de infraestrutura, enchentes, criminalidade, miséria, alcoolismo, descaso do poder público, assim como a favela paulistana. Zeli viveu ali seis anos. Não quis seguir o grupo de famílias transferidas pela prefeitura para o atual bairro da Restinga, na periferia da capital gaúcha (Monteiro, 2006, p. 98). Ilhota foi desfeita para dar passagem a uma avenida, como a favela do Canindé.

Em 1972, a empregada doméstica com apenas o primeiro grau escolar (atual ensino fundamental) começou a escrever sobre sua experiência. O seu relato sobre a vida dura na favela foi incentivado pela socióloga Enid Backes, para a qual trabalhava. Mas Zeli teve de esperar mais 20 anos. Ilhota: testemunho de uma vida, seu livro de memórias, só foi publicado em 1993, quando a Secretaria Municipal da Cultura de Porto Alegre criou a série Outras vozes, para publicar textos de escritores de classes populares e excluídos de círculos letrados.

Mulheres, negras, pobres, de pouca instrução formal, moradoras de favelas em centros urbanos na mesma época, que resolveram escrever sobre suas experiências em áreas de degradação, miséria e criminalidade. Pois bem: Carolina e Zeli têm mesmo muito em comum. Mas há diferenças também: Carolina queria ser escritora reconhecida nos círculos de letrados; Zeli queria relatar o que viveu e fazer as pazes com o passado. Dessas semelhanças entre Carolina e Zeli, surgem outros questionamentos a respeito das convicções de Bosi. Então Zeli e Carolina são dois acidentes, duas extraterrestres? São apenas dois casos notáveis, "difíceis de repetir-se"? As semelhanças entre elas são apenas coincidências? As respostas são desnecessárias, de tão óbvias.

Carolina estava em um grande centro econômico e foi encontrada por um jornalista que trabalhava em veículos de enorme circulação - Folha da Noite, do atual grupo Folha de S. Paulo, e depois na então renomada revista O Cruzeiro. Quarto de despejo vai para as bancas em 1960, no olho do furacão, em meio aos movimentos sociais em crescimento; leitores para os dramas vividos na favela não faltavam. O relato de Zeli tem um deslocamento de época de 30 anos entre sua rotina na favela e a 
publicação de seu livro. Carolina escrevia da favela ainda na favela; falava da fome sofrendo os efeitos dela. Zeli já tinha conquistado o sonhado terreno fora da favela, não vivia mais sob a ameaça. Era memória, não diário de passado recentíssimo. Estão aí algumas diferenças que podem explicar as repercussões distintas. Mas um sucesso de vendas não pode ser usado como argumento para encerrar uma discussão; não se levarmos em conta a obra de Moretti.

A existência de Zeli nos devolve o ânimo. Há outros casos a explorar, Carolina não é filho único. Dados quantitativos são possíveis, podemos ter esperança. Mas vão exigir mais tempo e esforço. A tarefa é exaustiva, porém necessária. Em Os pobres na literatura brasileira (1983), o sociólogo Roberto Schwarz reúne artigos de vários críticos literários que retratam a presença das classes populares nas nossas letras. Nessa obra, Carlos Vogt é um dos primeiros a perceber a estrutura narrativa de Carolina, "cujo ponto de sustentação principal é a presença obsedante da fome e da pobreza nas formas mais concretas de suas manifestações" (1983, p. 208).

Mas Carolina continua sendo peculiar: dos escritores analisados é a única pobre, que fala da periferia ainda na periferia. O restante dos artigos trata de personagens pobres construídos por homens letrados; de classe média, no mínimo. O esforço de Schwartz merece todo reconhecimento, mas Carolina ainda aparece como um caso à parte. Parece de outra ramificação, se usarmos os conceitos de Moretti. Em 1995, Maria José Motta Viana lança Do sótão à vitrine: memórias de mulheres. Carolina está entre elas, mas o foco da obra é a memorialística feminina. São depoimentos de todas as classes sociais, mas predomina a escrita da classe média ou alta, de mulheres letradas e artistas. Ainda não é isso que estamos perseguindo.

Em obra mais recente, Nelson de Oliveira inclui trechos de Quarto de despejo no livro Cenas de favela: as melhores histórias da periferia brasileira (2007). Ali Carolina não parece mais um caso tão peculiar assim. Escrevendo da periferia e na periferia, aparece o escritor Ferréz, um dos destaques de um grupo de autores de bairros pobres da capital paulistana. Ferréz é de Capão Redondo, na zona sul, região próxima de Parelheiros, bairro que Carolina escolheu para morar em um sítio depois da decepção com o mundo dos brancos letrados. Ela morreu ali, em 1977.

Carolina tornou-se uma importante referência para Ferréz e outros escritores da periferia urbana de São Paulo. É o que nos confirma Érica Peçanha do Nascimento, em Vozes marginais na literatura (2009). Na obra 
que se originou de sua dissertação de mestrado em antropologia social, ela não dedica nenhum capítulo a Carolina, nem tenta fazer uma pesquisa quantitativa ou cumulativa. Interessa-se mais em retratar o cenário daquele momento, o que já merece todo o mérito. Mas Érica Nascimento registra - e isso é o que mais nos interessa -, que vários desses autores citam a leitura de Quarto de despejo ao falar de sua formação literária.

O livro também reforça outra tese importante. Se a relação entre Carolina e o jornalista Audálio Dantas sempre foi tensa, a ponto de haver um rompimento a partir do segundo livro - Casa de alvenaria: diário de uma ex-favelada, de 1961 -, a posição dos novos escritores da periferia é de desconfiança aos círculos de letrados bem-nascidos e à academia. O letrado não é mais um parceiro de tão boa vontade assim. O pobre deixou de ser objeto da escrita; agora é sujeito. Não precisa de mediadores. "Pra mim, a primeira autora marginal foi Carolina de Jesus. Ela era negra, favelada e catava papelão. Escreveu o livro Quarto de despejo, que foi publicado em 40 países, ganhou dinheiro, mas cometeu o erro de 'entrar para sociedade'" (Ferréz apud Nascimento, 2009, p. 236).

Regina Dalcastagnè tem se dedicado a pesquisas quantitativas da literatura brasileira. Mas seu interesse em A personagem do romance brasileiro contemporâneo: 1990-2004 (2005) é, como o título deixa claro, o gênero romance publicado pelas três maiores editoras do país (Companhia das Letras, Record e Rocco) no período. Só esse enfoque já afasta grande parte dos autores da periferia que, quando conseguem, publicam em editoras pequenas ou independentes e preferem outros gêneros, como diários, memórias e narrativas breves. Mesmo assim, as conclusões preliminares da pesquisa já confirmam "o elitismo próprio do campo literário e a necessidade de democratização da produção artística" (Dalcastagnè, 2005, p. 16).

Segundo a pesquisa, que incluiu 258 obras, o autor de romance brasileiro é, na maioria, homem, branco, classe média, com idade entre 50 e 59 anos. Entre as profissões desses autores, lideram os jornalistas, os professores universitários, os escritores profissionais, os tradutores e os roteiristas (Dalcastagnè, 2005, p. 41). Nenhuma ocupação das classes subalternas surge na lista, ou pelo menos os casos são tão poucos que não aparecem na distribuição percentual. Entre as personagens do romance a coisa se altera. A principal ocupação dos homens é a de escritor, porque muitos autores gostam de falar de si mesmos. Mas o segundo nesse ranking é o bandido ou contraventor. Entre as 
personagens femininas, não faltam na lista de profissões a empregada doméstica e a prostituta (Dalcastagnè, 2005, p. 42).

Se do período entre Carolina e Ferréz - entre os anos de 1960 e 2000 não dispomos de dados quantitativos sobre a literatura vinda das nossas periferias urbanas, pelo menos temos disponíveis outras estatísticas, sociais e econômicas, que podem nos dar um norte. Moretti faria isso, pressuponho. Em 1960, ano de lançamento de Quarto de despejo, o nível de escolaridade do brasileiro era de 1,8 ano de estudo, segundo o Atlas da Exclusão Social no Brasil (Pochmann e Amorim, 2003). Carolina se inseria exatamente nessa média - o mérito dela está justamente no que conseguiu fazer com tão pouco tempo de vida escolar. Nesse mesmo ano, o gasto público com educação consumiu apenas $1,7 \%$ do produto interno bruto (PIB).

Não eram somente os movimentos sociais que agitavam a vida brasileira no final de 1950 e começo dos anos 1960. Também nascia nos Estados Unidos a chamada teoria do capital humano (educação significa trabalhador mais produtivo, e consumidor mais qualificado, numa explicação simplificada, é claro). O número de analfabetos - 46,5\% da população acima de 5 anos, segundo o mesmo atlas - passou a ser uma mancha na imagem internacional do Brasil. Em 2000, quando Ferréz já era apontado como uma promessa pela imprensa paulistana, o nível médio de escolaridade do brasileiro era de seis anos. O gasto público com educação subiu para $4 \%$ do PIB. O analfabetismo caiu para 18,5\%. Essas estatísticas ainda estão muito longe das de países desenvolvidos, mas a pequena alteração pode ajudar a explicar o aparecimento de outros autores com perfil social semelhante ao de Carolina.

Voltemos a Moretti. Se Carolina seria o começo da uma ramificação literária, e o grupo liderado por Ferréz em atividade no século XXI uma espécie de continuidade mais recente, um possível ponto de chegada e consolidação, é preciso pelo menos tentar descobrir uma sucessão de obras ao longo desse tempo. Entre Carolina e Ferréz, quais os padrões gerais? Provavelmente seria uma das perguntas feitas por Moretti. É preciso analisar esse processo cumulativo com distanciamento. É preciso sair das singularidades. É preciso perceber os ciclos intermediários. Mas como fazer isso sem dados quantitativos disponíveis? Onde encontramos uma Zeli podemos encontrar muitas outras. Então é preciso garimpar.

E novos casos vão aparecendo. Ainda na década de 1960, Vera Tereza de Jesus consegue publicar Ela e a reclusão: o condenado poderia ser você (1965), 
livro no qual narra sua vida de criança de rua, suas passagens pelo juizado de menores, pelo manicômio, seu passado de roubos e prostituição na capital paulista. Em 1970, no Rio de Janeiro, Dora de Oliveira publica Confissões de uma doméstica. Na década de 1980, os casos aumentam. Francisca Souza da Silva consegue publicar Ai de vós!: diário de uma doméstica (1983), com apoio da mulher para a qual trabalhava. Foi ela quem lhe deu "caneta e papel, incentivando-a escrever" (Perpétua, 2011, p. 2). Sandra Mara Herzer, transexual que mudou seu nome para Anderson Herzer, órfã de pai assassinado e filha de prostituta, escreve A queda para $o$ alto (1982), no qual relata seu passado de preconceito, drogas, álcool e internações na Febem. Suicida-se antes de o livro ser lançado.

Em 1997, surge outro best-seller, Cidade de Deus, de Paulo Lins, com a indicação editorial da antropóloga Alba Zaluar e do sociólogo Roberto Schwarz. Ex-morador do bairro da periferia carioca que leva o mesmo nome, Lins chegou à faculdade de letras, uma diferença em relação à Carolina que os níveis de escolaridade nacional mais recentes ajudam a explicar. O livro chegou ao cinema, e o filme chegou ao maior prêmio da indústria do cinema de Hollywood: o Oscar. Além de mais leitores, a periferia urbana brasileira ganhou espectadores. Em artigo, Schwarz defendeu que o livro "merece ser saudado como um acontecimento" (1999, p. 163). E disse mais: "Se por um lado o crime forma um universo à parte, interessante em si e propício à estetização, por outro ele não fica fora da cidade comum, o que proíbe o distanciamento estético, obrigando à leitura engajada, quando mais não seja por medo. Trata-se de uma situação literária com qualidades próprias" (Schwarz, 1999, p. 167).

Na década de 1990 também surgem as primeiras publicações independentes de escritores da periferia urbana de São Paulo. Aparece o poeta Sérgio Vaz, fundador da Cooperifa (Cooperativa Cultural da Periferia). Ferréz também publica poesia de forma independente, antes de lançar Capão pecado (2000). No mesmo ano, Esmeralda Carmo Ortiz publica Esmeralda. Por que não dancei?, no qual relembra período de sua vida, dos 8 aos 19 anos, em que viveu na praça da Sé, centro de São Paulo, e suas dezenas de internações na Febem. Ainda em 2000, Alessandro Buzo publica $O$ trem: baseado em fatos reais, no qual denuncia o descaso do transporte público que liga o centro ao extremo da zona leste da capital paulista, onde mora.

$\mathrm{Na}$ virada do século surgem livros escritos por ex-detentos paulistas: Diário de um detento, de Jocenir, e Memórias de um sobrevivente, de Luiz 
Alberto Mendes, ambos publicados em 2001. No mesmo ano, Ferréz viabiliza o primeiro de três números de um projeto de literatura em revista chamado Caros Amigos: Literatura marginal - A cultura de periferia. No total, participaram 48 escritores, na maior parte residente em São Paulo (Nascimento, 2009, p. 20). Entre os autores escolhidos, uma gaúcha: Laura Matheus, moradora de uma comunidade de pescadores em Pelotas (RS). Por causa da repercussão, consegue publicar por uma editora independente paulista seu primeiro livro, Barbiele (2008), aos 71 anos - ela se alfabetizou aos 50 anos.

Esse é um levantamento prévio, mas já mostra que Carolina está longe de ser o único "exemplo notável" vindo do mundo dos excluídos. Um "tento difícil de repetir-se" talvez seja apenas as suas vendas, cujas explicações sejam singulares demais para entrar no foco de interesse de Moretti. O que importa é que Carolina não está sozinha. Vem bem acompanhada por Zeli, Vera, Dora, Francisca, Herzer, Lins, Vaz, Esmeralda, Buzo, Jocenir, Mendes, Laura e Ferréz e outros tantos de uma ramificação, um galho de uma árvore nascido a partir de Carolina. Todos, como ela, são sujeitos da narrativa, esse é o grande legado da catadora de papel que ainda precisa ser reconhecido. Talvez Carolina não tivesse consciência disso, mas devemos a ela o momento em que o morador da periferia deixa de ser objeto, rejeita o mediador letrado e passa a falar por si mesmo.

\section{Referências}

BARBOSA, Zeli de Oliveira (1993). Ilhota: testemunho de uma vida. Porto Alegre: EU; Porto Alegre.

BOSI, Alfredo (2002). Literatura e resistência. São Paulo: Companhia das Letras.

DALCASTASGNÈ, Regina (2005). A personagem do romance contemporâneo: 1990 - 2004. Estudos de Literatura Contemporânea, Brasília, n. 26, jul./dez. 2005, p. 13-71.

MEIHY, José C. S. B; LEVINE, Robert M. (1994). Cinderela negra: a saga de Carolina Maria de Jesus. Rio de Janeiro: Editora da UFRJ.

MONTEIRO, Charles (2006). Outras narrativas da cidade: o relato autobiográfico de Zeli de Oliveira Barbosa em Ilhota: testemunho de uma vida. In: LOPES, Antonio Herculano. História e linguagens: texto, imagens, oralidade e representações. Rio de Janeiro: 7Letras. 
MORETTI, Franco (2008). A literatura vista de longe. Tradução de Anselmo Pessoa Neto. Porto Alegre: Arquipélago.

NASCIMENTO, Érica Peçanha do (2009). Vozes marginais na literatura. Rio de Janeiro: Aeroplano.

OLIVEIRA, Nelson de (Org.) (2007). Cenas de favela: as melhores histórias da periferia brasileira. Rio de Janeiro: Geração.

PERPÉTUA, Elzira Divina (2011). Literatura brasileira confessional: uma leitura de memórias marginais. In: SIMPÓSIO NACIONAL DE LETRAS E LINGUÍSTICA - SILEL, 14., 20 a 22 nov. 2013, Universidade Federal de Uberlândia. Anais... Uberlândia: EDUFU, 2011. v. 2, n. 2, p. 1-10.

POCHMANN, Márcio; AMORIM, Ricardo (Org.) (2003). Atlas da exclusão social no Brasil. São Paulo: Cortez. v. 2.

SCHWARZ, Roberto (Org.) (1983). Os pobres na literatura brasileira. São Paulo: Brasiliense.

SCHWARZ, Roberto (1999). Cidade de Deus. In: SCHWARZ, Roberto. Sequências brasileiras: ensaios. São Paulo: Companhia das Letras, p. 163-171.

VIANA, Maria José Motta (1995). Do sótão à vitrine: memórias de mulheres. Belo Horizonte: Editora da UFMG.

VOGT, Carlos (1983). Trabalho, pobreza e trabalho intelectual. In: SCHWARZ, Roberto (Org.). Os pobres na literatura brasileira. São Paulo: Brasiliense.

Recebido em outubro de 2015.

Aprovado em março de 2016.

\section{resumo/abstract/resumen}

\section{A árvore Carolina Maria de Jesus: uma literatura vista de longe}

Gilmar Penteado

Este artigo discute a literatura produzida por empregadas domésticas, catadores de lixo, prostitutas, meninos de rua, usuários de droga, internos de instituições para menores, detentos, quase todos trazendo a herança da dificuldade de acesso à educação formal. Antes personagens de escritores cultos de classe média que, num determinado momento histórico, tornaram-se autores dos próprios relatos. Nossa suposição é que esse momento ocorreu com Carolina Maria de Jesus, autora do bestseller Quarto de despejo. Mas como o sucesso não se repetiu em seus outros livros, ela foi tratada como um fenômeno isolado, difícil de repetir-se. Franco Moretti, crítico 
mordaz ao velho vício de se prender a singularidades, abre um novo caminho com sua obra A literatura vista de longe. Desde Carolina surgiu um grande número de autores que precisa ser estudado, quantificado, tabulado, com gráficos, mapas e árvores evolutivas, ou seja, as armas do crítico italiano. A partir dele, o artigo vislumbra uma ramificação que nasce em Carolina. O problema é a dificuldade em conseguir dados quantitativos, principal matéria-prima de Moretti, o que nos exige uma garimpagem que tem de começar o mais rápido possível.

Palavras-chave: literatura marginal, Carolina Maria de Jesus, Franco Moretti.

\section{The ramifications of Carolina Maria de Jesus: a literature seen from a distance}

\section{Gilmar Penteado}

This article discusses the literature produced by maids, garbage collectors, prostitutes, street children, drug users, inmates at detention centers for minors, detainees, individuals who carry the burden of a difficult access to formal education. Formerly the characters in the works of educated middle class authors, these subjects have, at a given moment, become writers of their own histories. We maintain that this is what happened with Carolina Maria de Jesus, the writer of the best-seller Quarto de despejo. However, as she did not experience the same success with her other books, she was treated as an isolated phenomenon, unlikely to repeat itself. Franco Moretti, a mordant critic to the old vice of holding to singularities, opens a new path with his work A literatura vista de longe. Since Carolina, a significant number of writers have appeared on the literary scene, who need to be studied, quantified, tabulated with graphics, maps and genealogical trees, in the other words examined using, the tools of the Italian critic. Taking as its point of departure Moretti's ideas, the article visualizes a development that begins with Carolina. Nonetheless, the problem lies in the difficulty in obtaining quantitative data, Moretti's main raw material, which requires a search for said materials that has to start as soon as possible.

Keywords: marginal literature, Carolina Maria de Jesus, Franco Moretti.

\section{Las ramificaciones de Carolina Maria de Jesus: una literatura vista desde la distancia}

\section{Gilmar Penteado}

En este artículo se analiza la literatura producida por empleadas domésticas, recolectores de basura, prostitutas, niños de la calle, usuarios de drogas, internos de instituciones para menores infractores, presos, todos herederos de la carga que conlleva el difícil acceso a la educación formal. Siendo anteriormente personajes de 
escritores cultos de clase media, en un determinado momento histórico todos ellos se convierten en autores de sus propias historias. Nuestra hipótesis es que este cambio se dió con Carolina Maria de Jesus, autora del éxito de ventas Quarto de despejo. Sin embargo, al no haber obtenido el mismo éxito con sus otros libros, la autora terminó siendo tratada como un fenómeno aislado. Franco Moretti, crítico mordaz del viejo vicio de preocuparse por singularidades, abre un camino alternativo de análisis con su obra A literatura vista de longe. A partir de Carolina surgió un gran número de autores que necesitan ser estudiados, cuantificados, tabulados con gráficos, mapas y árboles evolutivos, es decir, necesitan ser analizados con las herramientas del crítico italiano. Tomando como punto de partida las ideas de Moretti, el artículo visualiza el desarrollo de este proceso a partir de la aparición de Carolina. La dificultad yace en obtener datos cuantitativos, principal materia prima de Moretti, lo que nos exige una profunda investigación que tiene que empezar tan pronto como sea posible.

Palabras clave: literatura marginal, Carolina Maria de Jesus, Franco Moretti. 